\title{
The Effect of 3-Deoxy-3-fluoro-D-glucose on Saccharomyces cerevisiae
}

\author{
By B. Woodward, N. F. TAYlor and R. V. Brunt \\ Biochemistry Group, School of Biological Sciences, Bath University of Technology, Bath BA2 7 AY
}

(Received 7 July 1969)

In a previous communication (Brunt \& Taylor, 1967) evidence was presented indicating that resting cell suspensions of Saccharomyces cerevisiae (baker's yeast) oxidized 3FG* (Buck, Foster, Hems \& Weber, 1966) and that such treatment caused an inhibition of polysaccharide synthesis from glucose subsequently added to the cells.

It is the purpose of the present communication to show that the apparent oxidation of 3FG, originally reported by us, was due to contaminating ethanol, but, in addition, to show that pure crystalline 3FG is incorporated into the cell and thereby causes a block in the metabolism of both glucose and galactose.

Materials and methods. S. cerevisiae isolated as a single colony from baker's yeast (Distillers Co. Ltd., Bristol) was grown in a medium (Heredia, De la Fuente \& Sols, 1964) containing galactose and harvested after $20 \mathrm{hr}$. growth (stationary phase) at $30^{\circ}$ on a Gallenkamp rotary shaker at $250 \mathrm{rev} . / \mathrm{min}$. After two washes at $0^{\circ}$ in $0.05 \mathrm{M}$-sodium phosphate buffer, pH 6.8, the cells were suspended in the same buffer at the equivalent of $3.3 \mathrm{mg}$. dry wt./ml. (Brunt \& Taylor, 1967). To this suspension crystalline 3FG was added to give a final concentration of $5 \mathrm{~mm}$ and the mixture was incubated with shaking for $90 \mathrm{~min}$. at $30^{\circ}$. At this stage the cells were either washed and added to growth medium or incubated with glucose or galactose at a final concentration of $3 \mathrm{~mm}$. Measurements of growth were made turbidimetrically, of total and trichloroacetic acid-soluble polysaccharide as described by Barwell \& Brunt (1969), and of 3FG by the phenol$\mathrm{H}_{2} \mathrm{SO}_{4}$ method (Dubois, Gilles, Hamilton, Rebers \& Smith, 1956). Respiration rates were measured in a Warburg respirometer or by using the Clark oxygen-electrode system described by Chappell (1960). Glucose or galactose uptake was measured on filtrates of the cell suspensions by using the Glucostat reagent (Schweizerhall, Basle, Switzerland) or Galactostat reagent (Worthington Biochemical Corp., Freehold, N.J., U.S.A.) respectively. Ethanol was determined by the method of Bonnichsen (1965). The purity of crystalline 3FG was checked either by ascending silica-gel t.l.c. or by descending paper chromatography, with ethyl acetate-acetic acidwater (3:3:1, by vol.) as solvent.

* Abbreviation: 3FG, 3-deoxy-3-fluoro-D-glucose.
Results and discussion. On prolonged storage at $4^{\circ}$ the original syrupy 3FG preparation crystallized. This material had m.p. $105-107^{\circ},[\alpha]_{\mathrm{D}}^{22}+64^{\circ}$ (c 1.0 in water) (Found: $\mathrm{C}, 39.8 ; \mathrm{H}, 6.2 ; \mathrm{F}, 10.8$; $\mathrm{C}_{6} \mathrm{H}_{11} \mathrm{FO}_{5}$ requires $\mathrm{C}, 39 \cdot 6 ; \mathrm{H}, 6 \cdot 2 ; \mathrm{F}, 10 \cdot 4 \%$ ), and is now known to be an equal conglomerate of 3 . deoxy-3-fluoro- $\alpha$-D-glucose and 3-deoxy-3-fluoro$\beta$-D-glucose, which can be recrystallized from acetone. It gave a single component identical with the single component detected in the syrup (thinlayer $R_{F} 0.52$; paper $R_{F} 0.32$ ), but unlike the syrupy preparation was not oxidized by resting cell suspensions of $S$. cerevisiae. A re-examination of the original aqueous solution of the syrup showed that there was sufficient ethanol present to explain the apparent oxidation in its entirety. Since no ethanol could be detected in the crystalline material it is believed that the difference in behaviour is due to this ethanol and that 3FG is not oxidized by resting cell suspensions.

It was found that the phenol- $\mathrm{H}_{2} \mathrm{SO}_{4}$ carbohydrate reagent reacted quantitatively with $3 F G$, and by using this method a slow uptake of the analogue into the cells was detected. In these experiments a $75 \mathrm{ml}$. cell suspension prepared in buffer as described above was incubated under sterile conditions with 5 mM-3FG and at intervals samples were removed and membrane-filtered, and the filtrates assayed for phenol- $\mathrm{H}_{2} \mathrm{SO}_{4}$-positive material. Parallel control experiments showed that no phenol- $\mathrm{H}_{2} \mathrm{SO}_{4}$-positive material was present in the absence of 3FG. Reductions in the presence of 3FG indicated uptakes of 2,4 and $21 \mu$ moles at 1.5, 4 and $27 \mathrm{hr}$. respectively.

Such uptakes would be expected to give rise to significantly higher concentrations of phenol$\mathrm{H}_{2} \mathrm{SO}_{4}$-positive material within the cells, but, when after 3FG treatment washed and filtered cells were examined, the concentration was no higher than in parallel control cells. It was deduced from this that the incorporated 3FG is converted into products that no longer react with the phenol- $\mathrm{H}_{2} \mathrm{SO}_{4}$ reagent. Preliminary observations with an E.I.L. fluoride electrode indicate that free $\mathbf{F}$-ion is not released into either the intra- or the extra-cellular compartments.

Although no effects on growth were detected when 3FG was included directly in the growth medium, a $90 \mathrm{~min}$. preincubation of the inoculum with 3FG before addition of the growth medium 
Table 1. Effect of $3 F G$ treatment on subsequent glucose and galactose metabolism in $\mathrm{S}$. cerevisiae

Washed cells suspended in $0.04 \mathrm{M}$-phosphate buffer, pH6.8, at the equivalent of $10 \mathrm{mg}$. dry wt./3ml. were incubated with shaking at $30^{\circ}$ with $5 \mathrm{~mm}-3 \mathrm{FG}$ for $90 \mathrm{~min}$. At this point glucose or galactose was added to a final concentration of $3 \mathrm{~mm}$. Control cells incubated without 3FG also received an equivalent amount of sugar at this time. Results are given as means \pm s.E.M.; $n=$ no. of estimations. The data were analysed by the method of paired comparisons.

\begin{tabular}{|c|c|c|c|c|c|c|}
\hline & \multicolumn{3}{|c|}{ Glucose } & \multicolumn{3}{|c|}{ Galactose } \\
\hline & Control & 3FG & $\%$ change & Control & 3FG & $\%$ change \\
\hline $\begin{array}{l}\text { Sugar uptake ( } \mu \text { moles of hexose/min./ } \\
\text { l0mg. dry wt.) } \\
n=8\end{array}$ & $0 \cdot 32 \pm 0 \cdot 03$ & $0 \cdot 18 \pm 0 \cdot 03$ & $-44^{*}$ & $0 \cdot 19 \pm 0.03$ & $0 \cdot 17 \pm 0 \cdot 04$ & -10 \\
\hline $\begin{array}{l}\text { Oxygen uptake ( } \mu \text { g.atom of } 0 / \mathrm{min} . / \\
10 \mathrm{mg} \text {. dry wt.) } \\
n=4\end{array}$ & $0.63 \pm 0.01$ & $0 \cdot 61 \pm 0 \cdot 03$ & $-3 \cdot 2$ & $0 \cdot 18 \pm 0 \cdot 02$ & $0 \cdot 12 \pm 0 \cdot 02$ & $-33^{*}$ \\
\hline $\begin{array}{l}\text { Total polysaccharide accumulation } \\
\text { ( } \mu \text { moles of hexose equivalent/10 mg. } \\
\text { dry wt.) } \\
n=4\end{array}$ & $4 \cdot 38 \pm 0 \cdot 39$ & $1 \cdot 77 \pm 0 \cdot 33$ & $-60^{*}$ & $2 \cdot 63 \pm 0.55$ & $3 \cdot 63 \pm 0 \cdot 37$ & $+38^{*}$ \\
\hline
\end{tabular}

caused an increase in the lag period of up to $3 \mathrm{hr}$. No effects on doubling time or growth yield were detected.

Similarly, preincubation was necessary before effects on either glucose or galactose metabolism could be detected, and it appears that 3FG cannot compete for uptake in the presence of exogenous sugar.

The effects of this preincubation on subsequent glucose metabolism are shown in Table 1. In addition to the inhibition of polysaccharide synthesis previously reported, the uptake of glucose is also markedly inhibited. These experiments were carried out in the presence of residual exogenous 3FG and, since exogenous 6-deoxy-6-fluoro-Dglucose has been reported to have a direct effect on glucose uptake (Blackley \& Boyer, 1955), this explanation had to be considered here. However, when, after preincubation, exogenous 3FG was removed by washing twice with buffer, cells on resuspension in buffer alone showed similar inhibitions of both glucose uptake (39\%) and polysaccharide synthesis $(58 \%)$. This indicates not only that 3FG must be taken up by the cells to exert its effects, but that once incorporated it or its metabolites are not easily removed from the cells.

The small inhibition of the respiration rate with glucose seen after 3FG treatment as measured in the Warburg respirometer is not statistically significant. However, when the rate was determined with the oxygen electrode a transient but extensive inhibition was detected. At 30sec. after glucose addition 3FG treatment caused a $48 \%$ inhibition of rate, but between 1 and $2 \mathrm{~min}$. after addition this had fallen to $32 \%$. The reason for this is not clear at present, but may be occasioned by the inhibition of glucose uptake being very high in the early stages and rapidly falling to the value reported in Table 1.

Table 1 also shows the effect of 3FG treatment on galactose metabolism. The effects are quite different from the effects on glucose metabolism. The respiratory inhibition is very marked and is not transient when measured with either the oxygen electrode or the respirometer. In addition, no significant inhibition of galactose uptake was found and a significant increase in total polysaccharide synthesis is apparent. This increase was shown not to be due to an intracellular accumulation of free galactose, as the trichloroacetic acid-soluble fraction did not contain Galactostat-positive material. It also noteworthy that the synthesis of this soluble material (Barwell \& Brunt, 1969) was inhibited by $65 \%$ on 3FG treatment (control, 1.5; 3FG-treated, $0.5 \mu \mathrm{mole}$ of hexose equivalent accumulated $/ 10 \mathrm{mg}$. dry wt. of cells).

The effects on glucose metabolism could be consistent with the bound 3FG or its metabolites causing an inhibition of the active sugar-transport mechanism described by Rothstein \& Van Steveninck (1966). However, the effects noted on galactose metabolism are unlikely to be explained in terms of interference with transport mechanisms. It is more likely that the analogue or its metabolites causes an alteration in the activity of an enzyme or enzymes concerned with exogenous galactose degradation.

This work was in part supported by the Science Research Council (N.F.T.) and B.W. acknowledges receipt of a Science Research Council studentship. We acknowledge the expert technical assistance of Mrs Bridget Hunt. 
Barwell, C. J. \& Brunt, R. V. (1969). Arch. Mikrobiol.64, 315. Blackley, E. R. \& Boyer, P. D. (1955). Biochim. biophys. Acta, 16, 581.

Bonnichsen, R. (1965). In Methods of Enzymatic Analysis, p. 285. Ed. by Bergmeyer, H. U. New York: Academic Press Inc.

Brunt, R. V. \& Taylor, N. F. (1967). Biochem. J. 105, $41 \mathrm{c}$. Buck, K. W., Foster, A. B., Hems, R. \& Weber, J. M. (1966). Carbohyd. Res. 8, 137.
Chappell, J. B. (1960). In Biological Structure and Function, vol. 2, p. 71. Ed. by Goodwin, T. W. \& Lindberg, 0 . New York: Academic Press Inc.

Dubois, M., Gilles, K. A., Hamilton, J. K., Rebers, P. A. \& Smith, F. (1956). Analyt. Chem. 28, 350.

Heredia, C. F., De la Fuente, G. \& Sols, A. (1964). Biochim. biophys. Acta, 86, 216.

Rothstein, A. \& Van Steveninck, J. (1966). Ann. N.Y. Acad. Sci. 187, 606. 